\title{
Review
}

\section{Computer-Aided Diagnosis of Depression Using EEG Signals}

\author{
U. Rajendra Acharya ${ }^{\mathrm{a}-\mathrm{c}}$ Vidya K. Sudarshan ${ }^{\mathrm{a}}$ Hojjat Adeli $^{\mathrm{d}, \mathrm{e}}$ \\ Jayasree Santhosh ${ }^{c}$ Joel E.W. Koh ${ }^{a}$ Amir Adelid
}

${ }^{a}$ Department of Electronics and Computer Engineering, Ngee Ann Polytechnic and ${ }^{b}$ Department of Biomedical Engineering, School of Science and Technology, SIM University, Singapore, Singapore; 'Department of Biomedical Engineering, Faculty of Engineering, University of Malaya, Kuala Lumpur, Malaysia; Departments of ${ }^{\mathrm{d}}$ Neurology and e Neuroscience, Biomedical Engineering, Biomedical Informatics, and Electrical and Computer Engineering, The Ohio State University, Columbus, Ohio, USA

\section{Key Words}

Brain stimulation · EEG · Emotion · Depression · Linear methods $\cdot$ Nonlinear methods

\begin{abstract}
The complex, nonlinear and non-stationary electroencephalogram (EEG) signals are very tedious to interpret visually and highly difficult to extract the significant features from them. The linear and nonlinear methods are effective in identifying the changes in EEG signals for the detection of depression. Linear methods do not exhibit the complex dynamical variations in the EEG signals. Hence, chaos theory and nonlinear dynamic methods are widely used in extracting the EEG signal features for computer-aided diagnosis (CAD) of depression. Hence, this article presents the recent efforts on CAD of depression using EEG signals with a focus on using nonlinear methods. Such a CAD system is simple to use and may be used by the clinicians as a tool to confirm their diagnosis. It should be of a particular value to enable the early detection of depression.

(c) 2015 S. Karger AG, Basel
\end{abstract}

\section{Introduction}

According to the latest WHO report, depression affects more than 350 million people of all ages, making it as one of the most prevalent global diseases [1]. It is estimated that the largest proportion of people suffering from depression are women aged between 18 and 45 years [2]. In women, pregnancy and menopause are the main causes for depression. Depression can be treated using available effective treatments, but due to ignorance, untimely detection, misdiagnosis or improper medication people suffer from the disease worldwide. Untreated depression may lead to suicidal attempts. According to the 65th World Health Assembly (WHA) organized in 2012, the global burden of depression disorder is increasing and there is a need for a comprehensive, coordinated response from all health and social sectors at the country level [3].

Depression is a mental disorder characterized by persistent occurrences of lower mood states in the affected person and is usually perceived by friends or relatives. The symptoms of depression appear mostly as behavioural ones. Normally, the help of psychiatrists or
Vidya K. Sudarshan

Department of Electronics and Computer Engineering Ngee Ann Polytechnic

Singapore 599489 (Singapore)

E-Mail vidya.2kus@gmail.com 
Fig. 1. Block diagram of a typical computer-aided system for EEG-based diagnosis of depression.

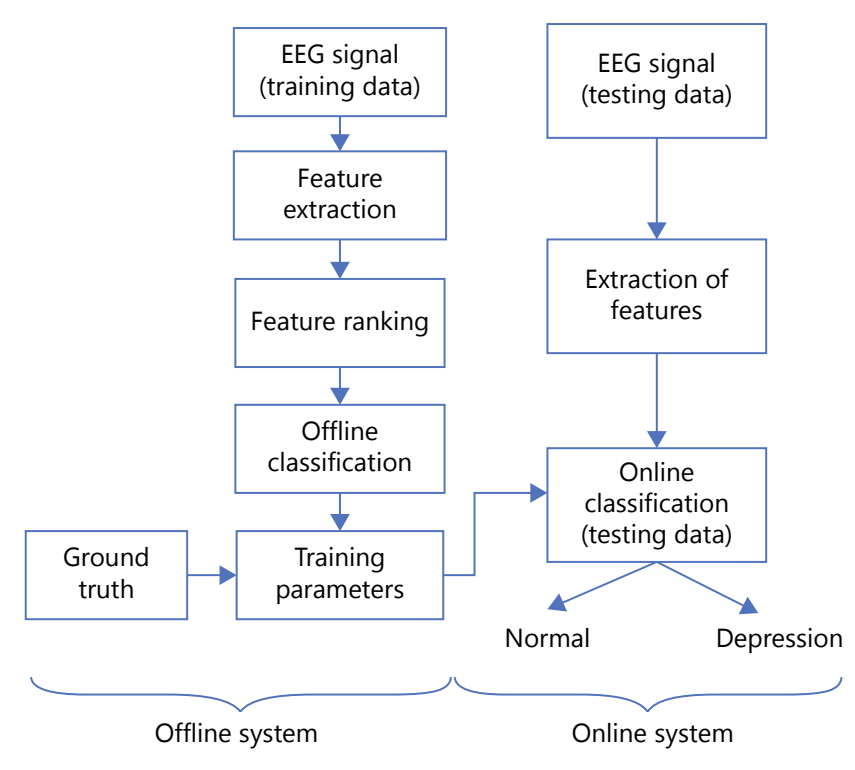

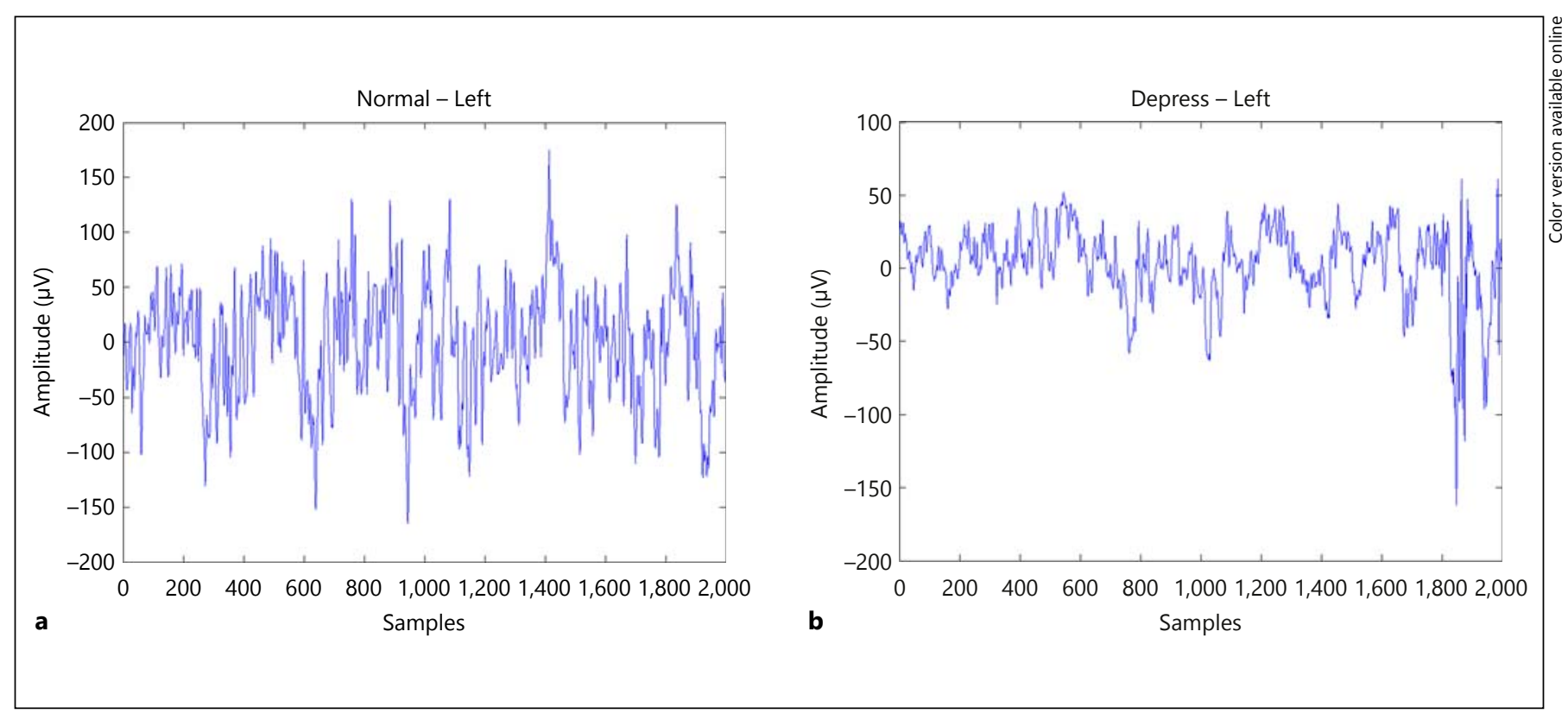

Fig. 2. Sample EEG signals used in this research from the left brain hemisphere: a normal; b depression.

counsellors is sought for diagnosis and treatment. The identification of depression in the early stage is crucial to prevent it from reaching a severe and irreversible state. Electroencephalogram (EEG) may be used as a tool for making an objective diagnosis of depression. This article presents the recent efforts on computer-aided diagnosis (CAD) of depression using EEG signals. Figure 1 shows a typical CAD system used for the classification of normal and depression EEG signals. Figure 2 shows sample normal and depression EEG data obtained from the left 
(FP1-T3) and right (FP2-T4) hemispheres of the brain. The flow of this review article is as follows: section 2 provides highlight on general EEG studies of depression using the clinical interpretation of EEG signals' features. Section 3 discusses the various studies conducted in the detection of depression from EEG signals using linear methods. The final section 4 focusses on the use of nonlinear methods by different researchers to extract the EEG signal features for CAD of depression.

\section{General EEG Studies of Depression}

Studies show that patients with depression have hemispheric asymmetry in their brain signals when compared to non-depressed subjects [4-7]. A preliminary study by Nandrino et al. [8] shows that the decrease in complexity [9] of brain functioning in patients with depression is a sign of a lower level of interaction with the environment. The study reports that the EEG dynamics is more predictable, that is, less complex, in depressed patients than in normal subjects. Pezard et al. [10] confirmed and extended the conclusion of Nandrino et al. [8]. Their study showed that patients differ significantly in their dynamical response to therapeutic interventions during first and recurrent episodes. Deslandes et al. [11] assessed the differences in EEG signal asymmetry of depressed and normal elderly subjects and observed the connections between depressive symptom measures and quality of life. They reported that EEG signal asymmetry at the alpha band in clinically depressed elderly adults are similar to that of younger depressed subjects when compared to normal subjects.

The resting frontal EEG alpha asymmetry is reliably assessed in clinically depressed patients; thus, it serves as a trait marker of risk for depression and other emotion-related psychopathology [12]. Debener et al. [13] explains the relationship between alpha EEG asymmetry and depression in patients on two separate occasions between 2 and 4 weeks apart. Their results show that the increased variability of anterior EEG asymmetry can be used as a characteristic feature or marker for depression detection from EEG signals. Recently Stewart et al. [14] used resting frontal EEG asymmetry as a marker of depression and showed that it is predominant in women.

Even though multiple courses of antidepressants are used to treat individuals with depression, the relationship between earlier treatment and the brain's response to future treatment is not known. Antidepressant drugs pres-

Automated EEG Analysis of Depression ent notable variations in human brain activity or function and are reflected in the EEG. The effects of drugs on the EEG vary and are often dose dependent. The effects of drugs include accentuation of beta activity, background slowing with decreased amplitude and frequency of the alpha rhythm, and intermixed theta and delta activity $[15$, 16].

The most common changes in EEG characteristics due to medications are slight increase of theta and excess beta activity. The medication causes an augmentation of voltage of beta activity on the EEG signal. Central nervous system (CNS) stimulants such as cocaine, methylphenidate and antidepressants may excite significant beta activity at low voltage $[17,18]$. High doses of several types of medications such as, lithium, phenothiazines and antidepressants, may evoke spikes due to delta and increase theta $[17,18]$.

Antidepressants with thymoleptic properties (e.g. impramine) generate a decline of alpha activity and an elevation of both slow and fast activities [19], while the antidepressant without thymoleptic properties (e.g. amitriptyline) produces slightly more distinct EEG pattern. In contrast, antidepressants with thymoretics properties (e.g. desipramine), induce decline of fast beta and an elevation of alpha activities. The antidepressant medications induce slight decline in the prefrontal brain activity [20].

A study by Davidson et al. [21] suggested that pronounced corresponding right anterior EEG activity acted as an indicator for the evolution of depression and anxiety problems. It was investigated and proved by experimental results that anterior and posterior EEG asymmetry patterns predicted the future occurrence of depression symptoms [22]. The study predicted that those with comparatively less right posterior EEG activity may complain higher depressive symptoms after a year [22], whereas particularly the frontal asymmetry of EEG alpha power indicated the risk for depression [23]. Using EEG signal processing, depression levels and evolution of depression to various disorders like sleep disorders and alcoholism were studied [24].

\section{Linear Methods}

A number of EEG studies based on linear methods found frontal asymmetry [14, 25-27] but reported different results in depressed patients. A bilateral increase in the frontal lobe alpha band activity [28], an increase in the 
frontal beta band activity $[28,29]$, and a reduction in the slow wave activity during sleep [30,31], are results observed by different researchers.

Knott et al. [32] suggested the EEG power as a useful tool for investigating brain regional mechanism in depressed patients. They reported that EEG measurements (amplitude, frequency and power) obtained using linear methods in depressed patients appeared to describe a pattern of aberrant inter-hemispheric asymmetry and a profile of frontal activation.

\section{Nonlinear Methods}

EEG signals are complex, nonlinear, and non-stationary in nature. The features of the signal vary with the age, diet, and mental state of the subject [33]. Linear methods may not be able to exhibit the complex dynamical variations in the EEG signals obtained from the highly complex and nonlinear-depressed brain system. Chaos theory and nonlinear dynamic methods are used to extract bispectrum, power spectrum, phase entropies, wavelet energy and entropy, correlation dimension, fractal dimension, largest Lyapunov entropy, approximate entropy, Hurst's exponent features have recently been used successfully for seizure detection and epilepsy diagnosis [34-41], diagnosis of the Alzheimer's disease [42], and study of depression [43-45] and sleep stages $[46,47]$. Thus, the authors advocate the use of nonlinear methods to extract the EEG signal features for CAD of depression.

A CAD system for EEG-based diagnosis of depression involves feature extraction, ranking, and classification steps. Different nonlinear methods can be used to extract features from the EEG signal to differentiate a depressive EEG from a healthy one such as Fractal Dimension (FD) $[48,49]$, Recurrence Quantification Analysis (RQA) [50, 51], Higher-Order Spectra (HOS) [52-54], sample entropy $[55,56]$, approximate entropy [57], Largest Lyapunov Exponent (LLE) [58], Hurst's exponent (H) [59] and Detrended Fluctuation Analysis (DFA) [60].

The purpose of feature ranking is to identify and rank the significance of the extracted features of the two groups (normal and depression). Most commonly the Student t-test [61] is used for this purpose, where a low p-value indicates the significance of the extracted features and the $t$-value is used to rank the features with higher values indicating clinically more significant features.

The highly ranked features are fed to a classification algorithm such as Support Vector Machine (SVM)
[62-64], Decision Tree (DT) [65], K-Nearest Neighbour (KNN) [65]. The ten-fold cross validation method is often used to train and select the best classifier, which achieves high classification accuracy with a minimum number of features. A few studies have applied nonlinear methods namely FD [66], wavelet-based energy [43] and entropies [44] to extract EEG signal features and artificial neural networks (ANN) [43] to classify EEG signal features into depression and normal behaviour. Ahmadlou et al. [66] investigate EEGs obtained from patients with Major Depressive Disorder (MDD) using the wavelet-chaos methodology developed by Adeli and associates earlier for EEG-based diagnosis of epilepsy [67] and Higuchi's and Katz's fractal dimension (HFD and KFD) $[68,69]$ as measures of complexity and nonlinearity. They compared frontal lobes (left and right) HFDs and KFDs in EEG full-band and various subbands of MDD and control groups with the goal of discovering relevant differences in terms of FDs between the two groups. They used the discovered FDs as input to a classifier, the enhanced probabilistic neural network (EPNN) [70-72], to differentiate the MDD from healthy EEGs. They reported an accuracy of $91.3 \%$ for MDD and healthy subjects' classification based on beta sub-band HFDs and concluded that the complexity of frontal EEG at beta sub-band may be used as a marker for diagnosis of MDD and for monitoring of its treatment.

Puthankattil et al. [43] extracted Relative Wavelet Energy (RWE) parameters from the Discrete Wavelet Transform (DWT) [73-78] coefficients and used ANN [79-81] to classify the EEG signal into normal and depressed classes. They claim an overall classification accuracy of $98.11 \%$ in discriminating the two classes. Ahmadlou et al. [82] presented a novel nonlinear method 'Spatiotemporal Analysis of Relative Convergence (STARC)' for the analysis of brain dynamics. The statistically significant STARC features selected using the analysis of variance (ANOVA) test are fed into the EPNN classifier to differentiate the MDD EEGs belonging to male and female patients respectively. They report 'significant differences of relative convergences of EEGs of intra-left temporal and frontleft temporal lobes at delta band between male and female patients'. Faust et al. [44] present a depression diagnosis support system using entropies extracted from the Wavelet Packet Decomposition (WPD) [83-85] coefficients of the EEG signal [61] and claim a classification accuracy of 99.5\% in discrimination of normal and depression EEG signals using the Probabilistic Neural Network (PNN) classifier. 


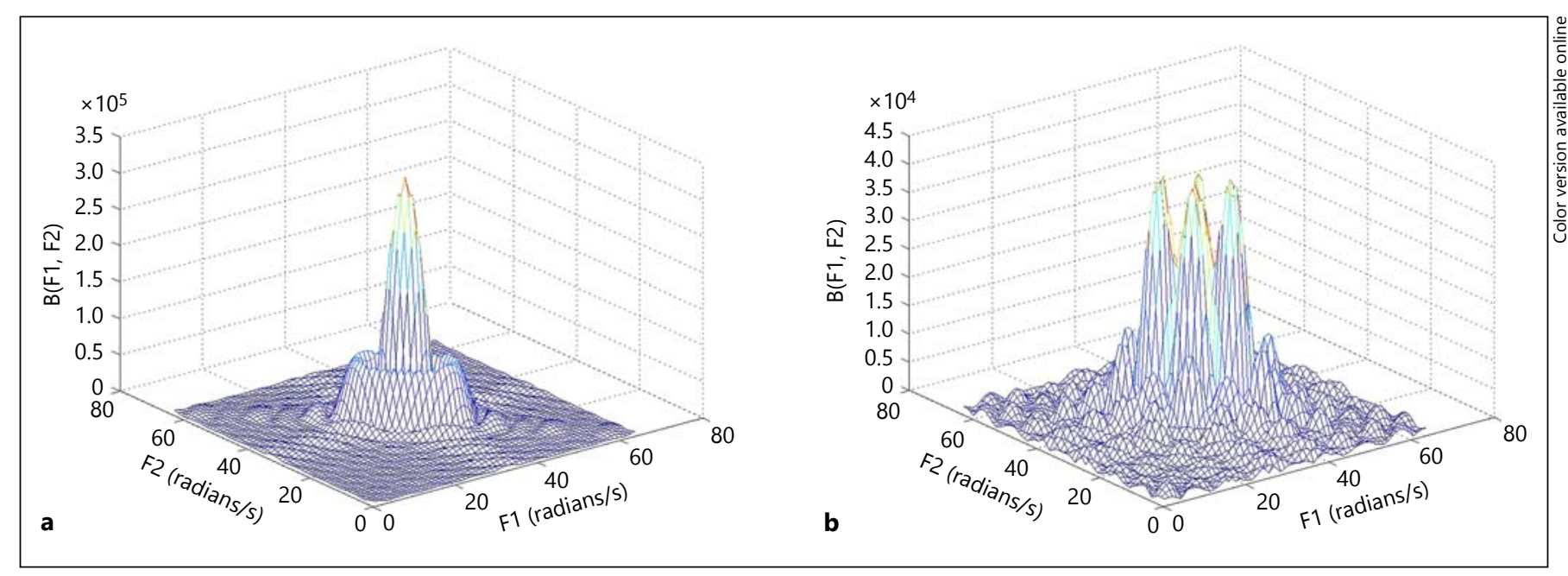

Fig. 3. Sample bispectrum magnitude plots of EEG signals from the left brain hemisphere shown in figure 2: a Normal; b depression.

Table 1. Summary of studies reporting on computer-aided EEG-based diagnosis of depression in chronological order

\begin{tabular}{|c|c|c|c|}
\hline Authors & Features used & Analysis method & Performance/conclusion \\
\hline Debener et al., 2000 & $\begin{array}{l}\text { Clinical features (EEG alpha } \\
\text { asymmetry) }\end{array}$ & Statistical analysis & $\begin{array}{l}\text { Increased variability of } \\
\text { anterior EEG asymmetry } \\
\text { may be a characteristic } \\
\text { feature for depression }\end{array}$ \\
\hline Knott et al., 2001 & $\begin{array}{l}\text { Clinical features (power, } \\
\text { frequency, asymmetry and } \\
\text { coherence measures) }\end{array}$ & Statistical analysis & Accuracy $=91.3 \%$ \\
\hline Puthankattil et al., 2012 & RWE & ANN classifier & Accuracy $=98.11 \%$ \\
\hline Ahmadlou et al., 2012 & KFD and HFD & Enhanced PNN classifier & Accuracy $=91.3 \%$ \\
\hline Ahmadlou et al., 2013 & STARC & Statistical analysis & $\begin{array}{l}\text { Significant difference } \\
\text { between EEGs of male } \\
\text { and female with MDD }\end{array}$ \\
\hline Faust et al., 2014 & WPD and entropies & PNN & Accuracy $=99.5 \%$ \\
\hline Acharya et al., 2015 & $\begin{array}{l}\text { FD, LLE, sample entropy, DFA, } \\
\text { Hurst's exponent, HOS, RQA }\end{array}$ & SVM, KNN, DT, NC, PNN & Accuracy $=98 \%$ \\
\hline
\end{tabular}

Bachmann et al. [86] compared the linear and nonlinear methods for the depression detection based on EEG signals. The linear method used to extract the features was the EEG frequency band power and the nonlinear method used was the HFD method. The authors claimed an accuracy of 88 and $94 \%$ using the linear and nonlinear methods, respectively, in detecting depression from the
EEG signal. Table 1 presents a summary of studies reporting on computer-aided EEG-based diagnosis of depression.

Even though a number of papers have been published using the nonlinear methods, there are other nonlinear methods [48-60, 87-98] that are worth exploring for the EEG-based diagnosis of depression. As an example, 


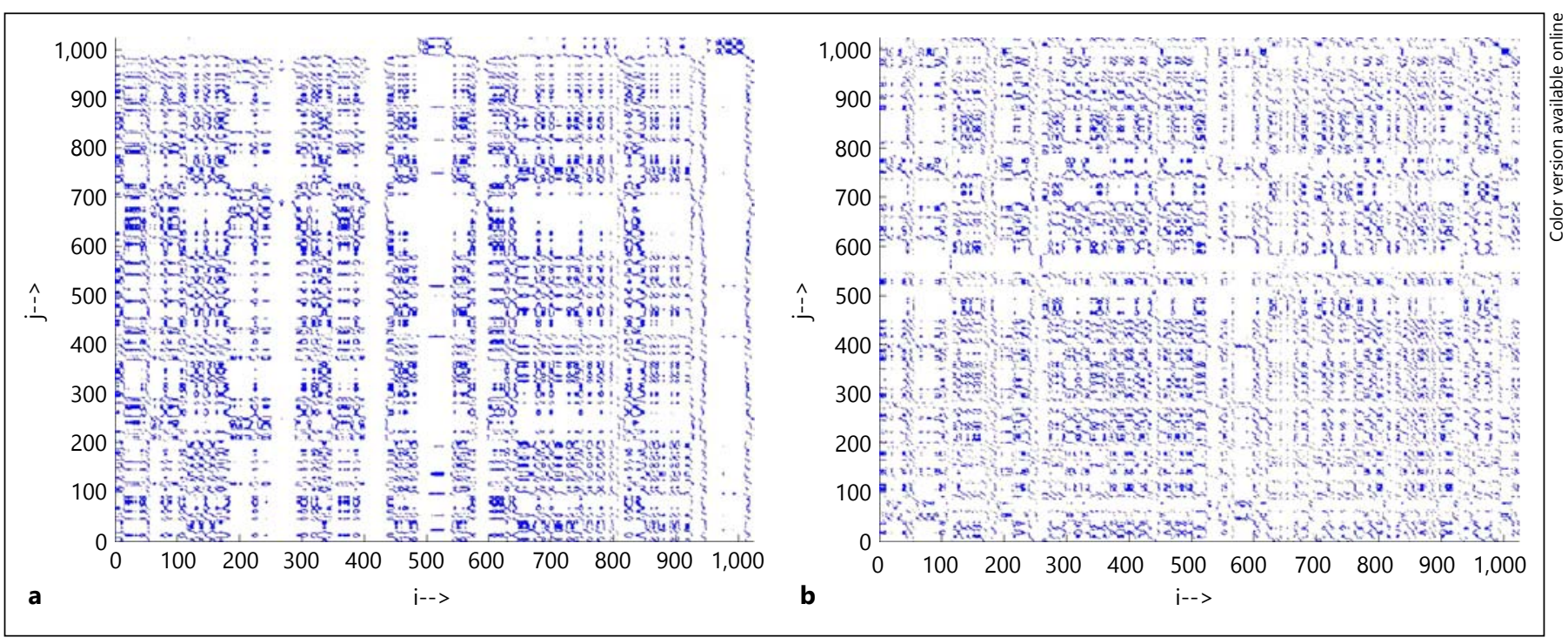

Fig. 4. Sample recurrence plots of EEG signals from the left brain hemisphere shown in figure 2: a Normal; b depression.

figures $3 \mathrm{a}$ and $\mathrm{b}$ show sample bispectrum magnitude plots of EEG signals from the left brain hemisphere for normal and depression subjects shown in figure 2, respectively. Similarly, figures $4 \mathrm{a}$ and $\mathrm{b}$ show sample recurrence plots of EEG signals from the left brain hemisphere for normal and depression subjects shown in figure 2, respectively. More peaks were observed in the bispectrum plot (fig. 3) between 0 and $20 \mathrm{~Hz}$ in the depression EEG signal compared with the normal EEG signal. Further, it was observed that the recurrence plot (fig. 4) was unique for each class; it is more rhythmic for the depression class.

\section{Conclusion}

In this article, a review of EEG-based diagnosis of depression was presented with a focus on CAD using nonlinear methods. Such a CAD system is simple to use and may be used by the clinicians as a tool to confirm their diagnosis. It should be of particular value for the early detection of depression. In a companion article [99], the authors presented a novel depression diagnosis index using the EEG signal and the following nonlinear methods HOS and RQA.

\section{References}

1 World Health Organization (WHO): World Suicide Prevention Day 2012. http://www. who.int/mediacentre/events/annual/world_ suicide_prevention_day/en.

2 National Alliance on Mental Illness (NAMI): Latina Women and Depression FACT Sheet, 2012.

3 WHO: World Health Assembly (WHA) Resolution 65th Report by Secretariat, 2012, pp 1-4. http://apps.who.int/gb/ebwha/pdf files/WHA65/A65_R4-en.pdf?ua=1 (accessed November 28, 2014).

4 Davidson RJ: Anterior electrophysiological asymmetries, emotion, and depression: conceptual and methodological conundrums. Psychophysiology 1998;35:607614.

5 Allen JJ, Iacono WG, Depue RA, Arbisi P: Regional electroencephalographic asymmetries in bipolar seasonal affective disorder before and after exposure to bright light. Biol Psychiatry 1993;33:642-646.

6 Gotlib IH, et al: Frontal EEG alpha asymmetry, depression, and cognitive functioning. Cogn Emot 1998;12:449-478.

-7 Henriques JB, Davidson RJ: Left frontal hypoactivation in depression. J Abnorm Psychol 1991;100:535-545.

-8 Nandrino JL, Pezard L, Martinerie J, el Massioui F, Renault B, Jouvent R, Allilaire JF, Widlöcher D: Decrease of complexity in EEG as a symptom of depression. Neuroreport 1994;5:528-530.

9 Deng Z, Zhang Z: Event-related complexity analysis and its application in the detection of facial attractiveness. Int J Neural Syst 2014;24: 1450026.

10 Pezard L, Nandrino JL, Renault B, el Massioui F, Allilaire JF, Müller F, Varela F, Martinerie $\mathrm{J}$ : Depression as a dynamical disease. Biol Psychiatry 1996;39:991-999.
11 Deslandes AC, de Moraes H, Pompeu FA, Ribeiro P, Cagy M, Capitão C, Alves H, Piedade RA, Laks J: Electroencephalographic frontal asymmetry and depressive symptoms in the elderly. Biol Psychol 2008;79:317-322.

12 Allen JJ, Urry HL, Hitt SK, Coan JA: The stability of resting frontal electroencephalographic asymmetry in depression. Psychophysiology 2004;41:269-280.

13 Debener S, Beauducel A, Nessler D, Brocke B, Heilemann H, Kayser J: Is resting anterior EEG alpha asymmetry a trait marker for depression? Findings for healthy adults and clinically depressed patients. Neuropsychobiology 2000;41:31-37.

14 Stewart JL, Bismark AW, Towers DN, Coan JA, Allen JJ: Resting frontal EEG asymmetry as an endophenotype for depression risk: sexspecific patterns of frontal brain asymmetry. J Abnorm Psychol 2010;119:502-512. 


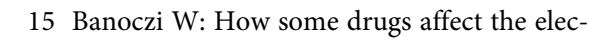
troencephalogram (EEG). Am J Electroneurodiagnostic Technol 2005;45:118-129.

16 Blume WT: Drug effects on EEG. J Clin Neurophysiol 2006;23:306-311.

17 Bauer G, Bauer R: EEG drug effects and central nervous system poisoning; in Niedermeyer E, Lopes da Silva FH (eds): Electroencephalography, ed 5. Philadelphia, Lippincott, Williams \& Wilkins, 2005, pp 701-724.

18 Van CA, Brenner RP: Drug effects and toxic encephalopathies; in Ebersole JS, Pedley TA (eds): Current practice of clinical electroencephalography, ed 3. Philadelphia, Lippincott, Williams \& Wilkins, 2003, pp 463-483.

$\checkmark 19$ Saletu B, Grünberger J, Rajna P, Karobath M: Clovoxamine and fluvoxamine-2 biogenic amine re-uptake inhibiting antidepressants: quantitative EEG, psychometric and pharmacokinetic studies in man. J Neural Transm 1980;49:63-86.

20 Hunter AM, Leuchter AF, Morgan ML, Cook IA: Changes in brain function (quantitative EEG cordance) during placebo lead-in and treatment outcomes in clinical trials for major depression. Am J Psychiatry 2006;163:14261432.

21 Davidson RJ: Cerebral asymmetry, emotion, and affective style; in Davidson RJ, Hugdahl K (eds): Brain Asymmetry. Cambridge, MIT Press, 1995, pp 361-387.

22 Blackhart GC, Minnix JA, Kline JP: Can EEG asymmetry patterns predict future development of anxiety and depression? A preliminary study. Biol Psychol 2006;72:46-50.

-23 Smit DJ, Posthuma D, Boomsma DI, De Geus EJ: The relation between frontal EEG asymmetry and the risk for anxiety and depression. Biol Psychol 2007;74:26-33.

24 Mallikarjun HM, Suresh HN: Depression level prediction using EEG signal processing. Contemporary computing and informatics (IC3I). IEEE International Conference, 2014, pp 928-933.

25 Iosifescu DV, Greenwald S, Devlin P, Mischoulon D, Denninger JW, Alpert JE, Fava M: Frontal EEG predictors of treatment outcome in major depressive disorder. Eur Neuropsychopharmacol 2009;19:772-777.

-26 Salustri C, Tecchio F, Zappasodi F, Bevacqua G, Fontana M, Ercolani M, Milazzo D, Squitti R, Rossini PM: Cortical excitability and rest activity properties in patients with depression. J Psychiatry Neurosci 2007;32:259-266.

-27 Fingelkurts AA, Fingelkurts AA, Rytsälä H, Suominen K, Isometsä E, Kähkönen S: Composition of brain oscillations in ongoing EEG during major depression disorder. Neurosci Res 2006;56:133-144.

28 Grin-Yatsenko VA, Baas I, Ponomarev VA, Kropotov JD: Independent component approach to the analysis of EEG recordings at early stages of depressive disorders. Clin Neurophysiol 2010;121:281-289.

29 Flor-Henry P, Lind JC, Koles ZJ: A sourceimaging (low-resolution electromagnetic tomography) study of the EEGs from unmed- icated males with depression. Psychiatry Res 2004;130:191-207.

- 30 Nissen C, Feige B, König A, Voderholzer U, Berger M, Riemann D: Delta sleep ratio as a predictor of sleep deprivation response in major depression. J Psychiatr Res 2001;35:155163.

31 Nissen C, Feige B, Nofzinger EA, Voderholzer U, Berger M, Riemann D: EEG slow wave activity regulation in major depression. Somnologie (Berl) 2006;10:36-42.

32 Knott V, Mahoney C, Kennedy S, Evans K: EEG power, frequency, asymmetry and coherence in male depression. Psychiatry Res 2001;106:123-140.

33 Acharya UR, Sree SV, Swapna G, Martis RJ, Suri JS: Automated EEG analysis of epilepsy: a review. Knowl Based Syst 2013;45:147-165.

34 Adeli H, Zhou Z, Dadmehr N: Analysis of EEG records in an epileptic patient using wavelet transform. J Neurosci Methods 2003; 123:69-87.

35 Adeli H, Ghosh-Dastidar S, Dadmehr N: A wavelet-chaos methodology for analysis of EEGs and EEG subbands to detect seizure and epilepsy. IEEE Trans Biomed Eng 2007;54: 205-211.

36 Chua KC, Chandran V, Acharya R, Lim CM: Automatic identification of epilepsy by HOS and power spectrum parameters using EEG signals: a comparative study. 30th Annual International IEEE EMBS Conference, Canada, 2008, pp 3824-3827.

37 Chua KC, Chandran V, Acharya UR, Lim CM: Automatic identification of epileptic electroencephalography signals using higherorder spectra. Proc Inst Mech Eng H 2009; 223:485-495.

38 Chua CK, Chandran V, Acharya RU, Min LC: Cardiac health diagnosis using higher order spectra and support vector machine. Open Med Inform J 2009;3:1-8.

39 Martis RJ, Acharya UR, Tan JH, Petznick A, Yanti R, Chua CK, Ng EY, Tong L: Application of empirical mode decomposition (emd) for automated detection of epilepsy using EEG signals. Int J Neural Syst 2012;22: 1250027.

40 Martis RJ, Acharya UR, Tan JH, Petznick A, Tong L, Chua CK, Ng EY: Application of intrinsic time-scale decomposition (ITD) to EEG signals for automated seizure prediction. Int J Neural Syst 2013;23:1350023.

41 Yuan Q, Zhou W, Yuan S, Li X, Wang J, Jia G: Epileptic EEG classification based on kernel sparse representation. Int J Neural Syst 2014; 24:1450015.

42 Adeli H, Ghosh-Dastidar S, Dadmehr N: A spatio-temporal wavelet-chaos methodology for EEG-based diagnosis of Alzheimer's disease. Neurosci Lett 2008;444:190-194.

43 Puthankattil SD, Joseph PK: Classification of EEG signals in normal and depression conditions by ANN using RWE and signal entropy. J Mech Med Biol 2012;12:1240019.

44 Faust O, Ang PAC, Puthankattil SD, Joseph PK: Depression diagnosis support system based on EEG signal entropies. J Mech Med Biol 2014; 14:1450035.

45 Hosseinifard B, Moradi MH, Rostami R: Classifying depression patients and normal subjects using machine learning techniques and nonlinear features from EEG signal. Comput Methods Programs Biomed 2013;109:339345.

46 Acharya UR, Faust O, Kannathal N, Chua T, Laxminarayan S: Non-linear analysis of EEG signals at various sleep stages. Comput Methods Programs Biomed 2005;80:37-45.

47 Acharya UR, Chua EC, Chua KC, Min LC, Tamura T: Analysis and automatic identification of sleep stages using higher order spectra. Int J Neural Syst 2010;20:509-521.

48 Mandelbrot BB: The fractal geometry of nature, ed 1. New York, WH Freeman and Company, 1982.

49 Higuchi T: Approach to an irregular time series on the basis of the fractal theory. Phys D 1988;31:277-283.

50 Marwan N, Thiel M, Nowaczyk NR: Cross recurrence plot based synchronization of time series. Nonlinear Process Geophys 2002;9: 325-331.

51 Marwan N, Romano MC, Thiel M, Kurths J: Recurrence plots for the analysis of complex systems. Phys Rep 2007;438:237-329.

52 Chua KC, Chandran V, Acharya UR, Lim CM: Computer-based analysis of cardiac state using entropies, recurrence plots and Poincare geometry. J Med Eng Technol 2006;30: 703-712.

53 Chua KC, Chandran V, Acharya UR, Lim CM: Cardiac state diagnosis using higher order spectra of heart rate variability. J Med Eng Technol 2008;32:145-155.

54 Chua KC, Chandran V, Acharya UR, Lim CM: Application of higher order spectra to identify epileptic EEG. J Med Syst 2011;35: 1563-1571.

55 Richman JS, Moorman JR: Physiological time-series analysis using approximate entropy and sample entropy. Am J Physiol Heart Circ Physiol 2000;278:H2039-H2049.

56 Zhang C, Wang H, Wang H, Wu MH: EEGbased expert system using complexity measures and probability density function control in alpha sub-band. Integr Comput Aided Eng 2013;20:391-405

57 Pincus SM, Keefe DL: Quantification of hormone pulsatility via an approximate entropy algorithm. Am J Physiol 1992;262:E741E754.

58 Wolf A, Swift JB, Swinney HL, Vastano JA: Determining Lyapunov exponents from a time series. Physica D 1985;16:285-317.

59 Dangel S, Meier PF, Moser HR, Plibersek S, Shen Y: Time series analysis of sleep EEG. Comput Assist Phys 1999;14:93-95.

60 Lee JM, Kim DJ, Kim IY, Park KS, Kim SI: Detrended fluctuation analysis of EEG in sleep apnea using MIT/BIH polysomnography data. Comput Biol Med 2002;32:37-47.

61 Box JF: Guinness, Gosset, Fisher, and small samples. Stat Sci 1987;2:45-52. 
-62 Li D, Xu L, Goodman E, Xu Y, Wu Y: Integrating a statistical background-foreground extraction algorithm and SVM classifier for pedestrian detection and tracking. Integr Comput Aided Eng 2013;20:201-216.

63 Vapnik V: Statistical Learning Theory. Willey, New York, 1998.

64 Burgess CJ: A tutorial on support vector machines for pattern recognition. Data Min Knowl Discov 1998;2:1-47.

65 Han J, Kamber M, Pei J: Data Mining: Concepts and Techniques, ed 2. Morgan Kaufmann, 2005, pp 292-295, 348-349.

-66 Ahmadlou M, Adeli H, Adeli A: Fractality analysis of frontal brain in major depressive disorder. Int J Psychophysiol 2012;85:206211.

67 Adeli H, Ghosh-Dastidar S: Automated EEGbased Diagnosis of Neurological Disorders Inventing the Future of Neurology. Boca Raton, Florida, CRC Press, Taylor \& Francis, 2010, pp 119-160.

68 Hsu WY: Single-trial motor imagery classification using asymmetry ratio, phase relation, wavelet-based fractal, and their selected combination. Int J Neural Syst 2013;23: 1350007.

69 Wang Y, Zhou W, Yuan Q, Li X, et al: Comparison of ictal and interictal EEG signals using fractal features. Int J Neural Syst 2013;23: 1350028.

70 Adeli H, Panakkat A: A probabilistic neural network for earthquake magnitude prediction. Neural Netw 2009;22:1018-1024.

-71 Ahmadlou M, Adeli H: Enhanced probabilistic neural network with local decision circles: a robust classifier. Integr Comput Aided Eng 2010;17:197-210

72 Sankari Z, Adeli H: Probabilistic neural networks for diagnosis of Alzheimer's disease using conventional and wavelet coherence. J Neurosci Methods 2011;197:165-170.

73 Kodogiannis VS, Amina M, Petrounias I: A clustering-based fuzzy wavelet neural network model for short-term load forecasting. Int J Neural Syst 2013;23:1350024.

-74 Perez G, Conci A, Moreno AB, Hernandez JA: Rician noise attenuation in the wavelet packet transformed domain for brain MRI. Integr Comput Aided Eng 2014;21:163-175

75 Amiri GG, Abdolahi AR, Hazaveh NK: Wavelet-based method for generating nonstationary artificial pulse-like near-fault ground motions. Comput-Aided Civ Inf 2014;29:758770
76 Dai H, Xue G, Wang W: An adaptive wavelet frame neural network method for efficient reliability analysis. Comput-Aided Civ Inf 2014; 29:801-814.

77 Katicha SW, Flintsch G, Bryce J, Ferne B: Wavelet denoising of TSD deflection slope measurements for improved pavement structural evaluation. Comput-Aided Civ Inf 2014; 29:399-415.

78 Amini F, Zabihi-Samani M: A wavelet-based adaptive pole assignment method for structural control. Comput-Aided Civ Inf Eng 2014;29:464-477.

79 Adeli H, Hung SL: Machine Learning - Neural Networks, Genetic Algorithms, and Fuzzy Systems. New York, John Wiley \& Sons, 1995.

80 Adeli H, Park HS: Neurocomputing for Design Automation. Boca Raton, Florida, CRC Press, 1998, pp 35-54.

81 Siddique N, Adeli H: Computational Intelligence - Synergies of Fuzzy Logic, Neural Networks and Evolutionary Computing. United Kingdom, Wiley, West Sussex, 2013, pp 103156.

82 Ahmadlou M, Adeli H, Adeli A: Spatiotemporal analysis of relative convergence of EEGs reveals differences between brain dynamics of depressive women and men. Clin EEG Neurosci 2013;44:175-181.

83 Jiang X, Adeli H: Wavelet packet-autocorrelation function method for traffic flow pattern analysis. Comput-Aided Civ Inf 2004;19:324337.

84 Jiang X, Mahadevan S, Adeli H: Bayesian wavelet packet denoising for structural system identification. Struct Control Health Monit 2007;14:333-356.

-85 Su WC, Huang CS, Chen CH, Liu CY, Huang HC, Le QT: Identifying the modal parameters of a structure from ambient vibration data via the stationary wavelet packet. Comput-Aided Civ Inf 2014;29:738-757.

86 Bachmann M, Lass J, Suhhova A, Hinrikus H: Spectral asymmetry and Higuchi's fractal dimension measures of depression electroencephalogram. Comput Math Methods Med 2013;2013:251638

87 Yuan Q, Zhou W, Yuan S, Li X, Wang J, Jia G: Epileptic EEG classification based on kernel sparse representation. Int J Neural Syst 2014; 24:1450015.

88 Osorio I: Automated seizure detection using EKG. Int J Neural Syst 2014;24:1450001.

89 Acharya UR, Vidya KS, Shreya B, Adeli H, Adeli A: Computer-aided diagnosis of alco- holism-related EEG signals. Epilepsy Behav 2014;41:257-263.

90 Hu M, Liang H: Perceptual suppression revealed by adaptive multi-scale entropy analysis of local field potential in monkey visual cortex. Int J Neural Syst 2013;23: 1350005.

-91 Acharya UR, Yanti R, Wei ZJ, Ramakrishnan MM, Hong TJ, Martis RJ, Min LC: Automated diagnosis of epilepsy using CWT, HOS and texture parameters. Int J Neural Syst 2013;23: 1350009.

92 Martis RJ, Acharya UR, Lim CM, Mandana KM, Ray AK, Chakraborty C: Application of higher order cumulant features for cardiac health diagnosis using ECG signals. Int $\mathrm{J}$ Neural Syst 2013;23:1350014.

-93 Rodríguez-Bermúdez G, García-Laencina PJ Roca-Dorda J: Efficient automatic selection and combination of EEG features in least squares classifiers for motor imagery braincomputer interfaces. Int J Neural Syst 2013; 23:1350015.

94 Lin LC, Ouyang CS, Chiang CT, Yang RC, Wu RC, Wu HC: Early prediction of medication refractoriness in children with idiopathic epilepsy based on scalp EEG analysis. Int J Neural Syst 2014;24:1450023.

$\$ 95$ Koppert M, Kalitzin S, Velis D, Lopes da Silva F, Viergever MA: Dynamics of collective multi-stability in models of distributed neuronal systems. Int J Neural Syst 2014;24: 1430004

96 Cong F, Phan AH, Astikainen P, Zhao Q, Wu Q, Hietanen JK, Ristaniemi T, Cichocki A: Multi-domain feature extraction for small event-related potentials through nonnegative multi-way array decomposition from low dense array EEG. Int J Neural Syst 2013;23: 1350006.

$97 \mathrm{Fu} \mathrm{R}$, Wang $\mathrm{H}$ : Detection of driving fatigue by using noncontact EMG and ECG signals measurement system. Int J Neural Syst 2014;24: 1450006.

98 Bauer PR, Kalitzin S, Zijlmans M, Sander JW, Visser GH: Cortical Excitability as a potential clinical marker of epilepsy: a review of the clinical application of transcranial magnetic stimulation. Int J Neural Syst 2014;24: 1430001.

99 Acharya UR, Vidya KS, Adeli H, Jayasree S, Koh JEW, Adeli A, Subha PD: Novel depression diagnosis index using nonlinear features in EEG signals. Eur Neurol 2015 (under review). 